\title{
Social-ecological correlates of accelerometer-measured occupational sitting among Japanese desk-based workers
}

\author{
Satoshi Kurita ${ }^{1 *}$ (D) Ai Shibata ${ }^{2}$, Kaori Ishii ${ }^{3}$, Mohammad Javad Koohsari ${ }^{3,4,5}$ and Koichiro Oka ${ }^{3}$
}

\begin{abstract}
Background: Although the main targets for reducing workplace sedentary behavior have been clarified, only a few studies have examined the association between social-ecological factors and workplace sedentary behavior for effective intervention. The present study aimed to examine the social-ecological factors of workplace sedentary behavior among Japanese sedentary workers.

Methods: Participants were recruited via a cross-sectional mail survey targeting randomly sampled 6000 middle-aged people dwelling in Matsuyama-city and Koto-ku in Japan. Participants answered a questionnaire on social-ecological factors, recorded their work time in a diary, and wore a triaxial accelerometer during waking time for 7 consecutive days. Workplace sedentary behavior was measured using accelerometer and was referred to as the work time in the recorded diary. Full-time workers who had mainly sitting work and valid accelerometer data were included in the analysis. Workplace sedentary variables were sedentary breaks per sedentary hour, sedentary time, and $\geq 30$ min bouts of sedentary time. The associations between each sedentary variable and social-ecological factors were explored by conducting three multiple linear regression analyses adjusting for sociodemographic and health-related factors.
\end{abstract}

Results: A total of 227 participants (133 men, mean age $49.9 \pm 6.9$ years) were included in the analysis. In the overall sample, "typically seeing work colleagues take sedentary breaks" was significantly associated with more sedentary breaks (B [95\% confidence interval $\{C \mid\}=1.40$ [0.07 to 2.73]) and shorter $\geq 30$-min bouts of sedentary time $(\mathrm{B}[95 \% \mathrm{Cl}]=-7.08[-13.75$ to -0.40$])$. "I am motivated to take sedentary breaks" had an unfavorable association with less sedentary breaks $(\mathrm{B}[95 \% \mathrm{Cl}]=-1.36[-2.61$ to -0.12$])$ and longer sedentary time $(\mathrm{B}[95 \% \mathrm{Cl}]=4.15[0.29$ to 8.00$]$ ). In male workers, "Too stressed to take sedentary breaks" was significantly associated with less sedentary breaks (B $[95 \% \mathrm{Cl}]=-5.6[-9.17$ to -2.02$]$ ).

Conclusions: Seeing work colleagues take sedentary breaks may be important for reducing workplace sedentary behavior. Those who are more sedentary are motivated to take sedentary breaks. Male workers who feel the need to take sedentary breaks at work are more sedentary.

Keywords: Workplace, Sedentary behavior, Determinants, Environment

\footnotetext{
* Correspondence: kuritoshi@ncgg.go.jp

${ }^{1}$ Department of Preventive Gerontology, Center for Gerontology and Social

Science, National Center for Geriatrics and Gerontology, Obu, Aichi, Japan

Full list of author information is available at the end of the article
}

(c) The Author(s). 2019 Open Access This article is distributed under the terms of the Creative Commons Attribution 4.0 International License (http://creativecommons.org/licenses/by/4.0/), which permits unrestricted use, distribution, and reproduction in any medium, provided you give appropriate credit to the original author(s) and the source, provide a link to the Creative Commons license, and indicate if changes were made. The Creative Commons Public Domain Dedication waiver (http://creativecommons.org/publicdomain/zero/1.0/) applies to the data made available in this article, unless otherwise stated. 


\section{Background}

Excessive sedentary behavior is a risk factor of several chronic diseases such as cardiovascular disease, stroke, some cancers, and musculoskeletal diseases [1, 2]. In high-income countries, sedentary jobs have rather increased along with technology advancement, which induces automation and efficiency, and workplaces have become a setting where excessive sedentary behaviors occur [3]. For example, Japanese sedentary workers dwelling in two urban areas spent $6.4 \mathrm{~h}$ performing sedentary work (69.3\% of work hours), which was approximately $3 \mathrm{~h}$ more than time to perform other more physically active tasks including standing, walking, and physical labor task [4].

To reduce workplace sedentary behavior, several interventions have been employed, and the effects have been revealed $[5,6]$. Breaking sedentary time is a widely feasible method of reducing sedentary time [6]. Additionally, to maximize the effects of the intervention, the factors correlated with workplace sedentary behavior have been explored. There have been many studies examining sociodemographic and health-related factors of workplace sedentary behavior [7-14]. Male sex, younger age, level of education, and higher body mass index (BMI) were among the related factors [8]. Another study found that men reported more short physical activity breaks than women during work hours [7]. Moreover, higher educated workers and young women were more likely to spend more work-related sitting time [13].

Although the potential targets for intervention have been clarified, there is lack of evidence supporting the relationship between social-ecological factors and workplace sedentary behavior for effective intervention [7, 10]. Social-ecological framework considers the complex interplay between individual, interpersonal, and environmental (community, organizational, build environmental, and political) factors, which are essential to promote physical activity [15]. For instance, in workplace sedentary behavior, work-specific individual (job type and work engagement), cultural (lunch away from the desk, walking at lunch and face-to-face interaction), physical (personal printer and office type) and organizational factors (sector) were associated with sedentary time [10].

Another study conducted in Australia explored the effects of social-ecological factors for sedentary breaks during working hours and found that awareness toward sedentary break (intrapersonal factor) was associated with increased sedentary breaks during sedentary times [7]. This study targeted only Australian workers; measured sedentary breaks by self-reporting, which contained recall bias; and did not adjust the covariates such as the sociodemographic factors in the analysis; hence, whether the above factors are important for any workers remains controversial. Although the study set only sedentary breaks as the outcome, if the associations between social-ecological factors of workplace sedentary breaks and sedentary time are also determined, the results will not only show increase in sedentary breaks but also reduction in sedentary time.

Therefore, this study aimed to explore the socialecological correlates of accelerometer-measured workplace sedentary behavior, including sedentary breaks, sedentary time, and prolonged bouts of sedentary time, among Japanese sedentary workers. As reports have shown that there were different correlates among male and female workers [7, 13], overall and sex-stratified analyses were conducted.

\section{Method}

\section{Study design and procedure}

Cross-sectional data of a project that investigated the association between neighborhood environment and sedentary behavior among Japanese adults aged 40-64 years were used in this study. A postal survey was conducted targeting middle-aged people dwelling in Matsuyama City in Ehime Prefecture, Japan, from July to December 2013 and in Koto Ward in Tokyo from April 2014 to February 2015. Details of the data selection was described elsewhere [16]. In brief, invitation letters were sent to 6000 potential participants who were randomly elected from the resident register. Participants who responded to the invitation were asked to fill out an informed consent form, wear an accelerometer, record their activities in a diary, and respond to a questionnaire. The study was approved by the Research Ethics Committee, Waseda University, Japan (2012-269, 2013-264).

A total of 864 participants (final response rate of $14.4 \%)$ responded to the invitation letters, and 778 participants finished the data collection. The participants indicated their working status (full time job, part-time job, no job, full-time homemaker, or student) and main occupational task (sitting task or desk work, standing task, walking task, or physical labor task) in the questionnaire. Among 297 participants who had full-time jobs and mainly sitting task or desk work and had valid accelerometer data with no missing variables $(n=227)$ were included in this study.

\section{Measurement of sedentary behavior and physical activity} Sedentary behavior and physical activity were measured using a triaxial accelerometer, Active style Pro HJA$350 I T$ (Omron Health Care Co., Ltd., Kyoto, Japan). Participants were asked to wear it on the left side of the waist for 7 consecutive days. This accelerometer has been validated for measuring physical activity and sedentary behavior in a controlled laboratory setting $[17,18]$ and has acceptable criterion-related validity of sedentary variables against activPAL with built-in inclinometer in a 
free-living setting [19]. The accelerometer can accurately calculate the participants' sedentary time especially when they have higher sedentary level. Although the accelerometer cannot discriminate between sitting and static standing postures, it can overestimate sedentary breaks without systematic error. One-minute epoch length was employed for data collection. Accelerometer data were processed using an Omron health management software, BI-LINK for physical activity professional edition ver 1.0 and custom software (Custom-written Macro program). Work hours were measured from the time the participants performed the task until the time they finished the task and recorded it in the activity diary. Valid accelerometer data of a work day were defined as $\geq 75 \%$ wear time during work hours [20] excluding $\geq 60$ consecutive 0.9 Metabolic equivalents (METs) with allowance of up to 2 min of $\leq 1.0$ METs. Those who had more than three valid work days were included in the analysis.

The activity intensity thresholds were 0.9-1.5 METs for sedentary behavior, and $\geq 3.0$ METs for moderate-tovigorous intensity physical activity (MVPA). Sedentary time was calculated from the sum of the minutes when the accelerometer measured sedentary time. A break in sedentary time was defined as an interruption in sedentary time, which occurred from a minute identified as sedentary to an adjacent following minute identified as not sedentary. Sedentary bout was defined as the start and end of the sedentary time period [21]. Sedentary variables were expressed as total sedentary time (\%wear time), $\geq 30$-min bouts of sedentary time (\%sedentary time), and breaks in sedentary time (times per sedentary hour).

\section{Social-ecological factors}

Social-ecological factors including individual factors, social factors, and work environmental factors were assessed using eight statements with a four-point response scale (Additional file 1) adapted from a questionnaire developed by a previous study conducted in Australia [7]. The original questionnaire comprised 13 statements with a five-point response scale [7]. However, three of the researchers (KO, AS, and KI) modified the questionnaire to make it more applicable to the Japanese workplace and midpoint response style of the Japanese people [22]. These included five statements related to individual factors ("Don't have enough time to take sedentary breaks," "Don't have enough energy to take sedentary breaks," "Sedentary breaks are a low priority," "Too stressed at work to take sedentary breaks," and "I am motivated to take sedentary breaks"), two statements related to social factors ("I typically see work colleagues take sedentary breaks" and "Company should encourage short breaks"), and one statement related to work environmental factor ("There is limited space available at my workplace for me to take a short physical activity break"). All questions were answered using a four-point Likert scale (strongly agree to strongly disagree), which was dichotomized into agree/strongly agree and disagree/strongly disagree for the analysis.

\section{Sociodemographic factors}

Sociodemographic information, including age, sex, and area of residence (Matsuyama City; Koto ward), were obtained from the basic resident register. Other factors were obtained using a self-report questionnaire: education level (high school or lower, 2-year college, or university degree or higher education), household income ( $<5$ million, $\geq 5$ million to $<7$ million, $\geq 7$ million to $<10$ million, or $\geq 10$ million), and marital status (currently single or married).

\section{Health-related factors}

BMI and weekly MVPA were used as health-related factors. BMI was calculated from the self-reported height and weight and dichotomized into normal weight $\left(<25.0 \mathrm{~kg} / \mathrm{m}^{2}\right)$ and overweight and obese $\left(\geq 25.0 \mathrm{~kg} / \mathrm{m}^{2}\right)$ considering the imprecision of self-reporting. Weekly MVPA was calculated from the accelerometer data by weighted average of workday and non-work day $([5 \times$ work day $+2 \times$ non-work day $] / 7)$.

\section{Statistical analysis}

Descriptive statistics of sociodemographic factors, health-related factors, and sedentary variables were summarized. In order to interpret how sedentary variables, which were continuous variables, change according to each social-ecological factor, multiple linear regressions with forced entry method were conducted, and the linear associations between social-ecological factors and sedentary variables were explored. Individual, social, and work environmental factors were included as independent variables in the models, and sociodemographic and health-related factors were included as adjusted variables. Unstandardized regression coefficient (B) and 95\% confidence intervals (95\% CI) of each factor for sedentary variables were calculated. Multicollinearity was not observed in any factor. Statistical significance was set at a level of 0.05 . All analyses were conducted using IBM SPSS Statistics 25.

\section{Results}

The characteristics of 227 participants (mean age: $49.9 \pm 6.9$ years, men: $58.6 \%$ ) are summarized in Table 1 . More than half of the participants lived in Koto Ward (58.6\%) and were highly educated (56.8\% had university degree or higher education). The mean breaks in sedentary time, total sedentary time, and $\geq 30$-min bouts of sedentary time during work hours were $8.5 \pm 4.4$ times, $69.8 \pm 13.7 \%$ wear time, and $31.5 \pm 21.5 \%$ wear time, respectively. There were significant sex differences in these sedentary variables (all $p<0.01$ ), 
Table 1 Characteristics of participants and sedentary variables during work hours

\begin{tabular}{|c|c|c|c|c|c|}
\hline & & $\begin{array}{l}\text { Total } \\
(n=227)\end{array}$ & $\begin{array}{l}\text { Male } \\
(n=133)\end{array}$ & $\begin{array}{l}\text { Female } \\
(n=94)\end{array}$ & $\begin{array}{l}p \text { for sex } \\
\text { difference }^{a}\end{array}$ \\
\hline \multicolumn{6}{|l|}{ Socio-demographic factors } \\
\hline Age & & $49.9 \pm 6.9$ & $50.5 \pm 7.2$ & $49.1 \pm 6.5$ & 0.15 \\
\hline \multirow[t]{2}{*}{ Area of residence } & Matsuyama City & $94(41.4)$ & $57(42.9)$ & $37(39.4)$ & 0.60 \\
\hline & Koto Ward & $133(58.6)$ & $76(57.1)$ & $57(60.6)$ & \\
\hline \multirow[t]{3}{*}{ Education } & High school or lower & $56(24.7)$ & $29(21.8)$ & $27(28.7)$ & $<0.01$ \\
\hline & College & $42(18.5)$ & $14(10.5)$ & $28(29.8)$ & \\
\hline & University or higher & $129(56.8)$ & $90(67.7)$ & $39(41.5)$ & \\
\hline \multirow[t]{4}{*}{ Income } & $<5$ million & 79 (34.8) & $31(23.3)$ & $48(51.1)$ & $<0.01$ \\
\hline & $\geq 5$ million to $<7$ million & $40(17.6)$ & $21(15.8)$ & $19(20.2)$ & \\
\hline & $\geq 7$ million to $<10$ million & $58(25.6)$ & $44(33.1)$ & $14(14.9)$ & \\
\hline & $\geq 10$ million & $50(22)$ & $37(27.8)$ & $13(13.8)$ & \\
\hline \multirow[t]{2}{*}{ Marital status } & Single & $58(25.6)$ & $17(12.8)$ & $41(43.6)$ & $<0.01$ \\
\hline & Married & $169(74.4)$ & $116(87.2)$ & $53(56.4)$ & \\
\hline \multicolumn{6}{|l|}{ Health-related factors } \\
\hline \multirow[t]{2}{*}{ BMl } & $<25 \mathrm{~kg} / \mathrm{m}^{2}$ & $172(75.8)$ & $92(69.2)$ & $80(85.1)$ & $<0.01$ \\
\hline & $\geq 25 \mathrm{~kg} / \mathrm{m}^{2}$ & $55(24.2)$ & $41(30.8)$ & $14(14.9)$ & \\
\hline Weekly average MVPA & & $6.7 \pm 3.1$ & $6.9 \pm 3.2$ & $6.5 \pm 2.8$ & 0.33 \\
\hline \multicolumn{6}{|l|}{ Sedentary variables during work hours } \\
\hline Sedentary time (\%wear time) & & $69.8 \pm 13.7$ & $72.0 \pm 13.0$ & $66.8 \pm 14.2$ & $<0.01$ \\
\hline $\begin{array}{l}\geq 30 \text {-min bouts of sedentary time } \\
\text { (\% sedentary time) }\end{array}$ & & $31.5 \pm 21.5$ & $35.7 \pm 20.4$ & $25.5 \pm 21.7$ & $<0.01$ \\
\hline Sedentary breaks per sedentary hour & & $8.5 \pm 4.4$ & $7.7 \pm 3.9$ & $9.7 \pm 4.7$ & $<0.01$ \\
\hline
\end{tabular}

Values were expressed as $\mathrm{n}(\%)$ or mean $\pm \mathrm{SD}$

$B M I$ Body mass index, MVPA Moderate-to-vigorous physical activity

${ }^{a}$ Categorical variables and continuous variables were compared using the $x^{2}$ test and ANOVA, respectively

which indicated that male workers had more sedentary behavior than female workers.

The associations between social-ecological factor and sedentary variables in the multiple linear regression models are summarized in Table 2 for sedentary breaks per sedentary hour. The sedentary break of the overall sample was positively associated with "Typically seeing work colleagues take sedentary breaks" [B $(95 \% \mathrm{CI})=$ 1.40 (0.07 to 2.73)] and negatively associated with "I am motivated to take sedentary breaks" [B $(95 \% \mathrm{CI})=-1.36$ $(-2.61$ to -0.12$)]$. For male workers, "Too stressed to take sedentary breaks" was significantly associated with less sedentary breaks $[\mathrm{B}(95 \% \mathrm{CI})=-5.6(-9.17$ to 2.02)], while for female workers, "I am motivated to take sedentary breaks" was significantly associated with less sedentary breaks [B $(95 \% \mathrm{CI})=-2.37(-4.6$ to -0.13$)]$.

In total sedentary time and $\geq 30$-min bouts of sedentary time, opposite results regarding sedentary breaks were observed (Tables 3 and 4). For overall sample, "I am motivated to take sedentary breaks" and "Typically seeing work colleagues take sedentary breaks" were respectively associated with longer total sedentary time
[B $(95 \% \mathrm{CI})=4.15(0.29$ to 8.0$)]$ and shorter $\geq 30$ - $\mathrm{min}$ bouts of sedentary time $[\mathrm{B}(95 \% \mathrm{CI})=-7.08(-13.75$ to - 0.40)]. In male workers, too stressed to take sedentary break was significantly associated with longer total sedentary time $[\mathrm{B}(95 \% \mathrm{CI})=18.65(7.04$ to 30.25$)]$ and $\geq$ 30 -min bouts of sedentary time $[\mathrm{B}(95 \% \mathrm{CI})=34.79$ (15.48 to 54.09)]. In addition, male workers who reported that they did not have enough time to take sedentary breaks had significantly shorter sedentary time $[\mathrm{B}(95 \% \mathrm{CI})=-8.32(-16.46$ to -0.19$)]$.

\section{Discussion}

This study examined the associations of social-ecological factors with objectively assessed workplace sedentary behavior among Japanese workers who have desk work. The findings showed that some social-ecological factors were significantly associated with not only sedentary breaks but also with other sedentary variables after adjusting for sociodemographic and health-related factors. To our knowledge, only one previous study has examined the associations of social-ecological factors with sedentary break and workplace sedentary behavior [7]. 
Table 2 Multiple linear regression analyses on the contribution of social ecological factors to sedentary breaks per sedentary hour

\begin{tabular}{|c|c|c|c|c|c|c|}
\hline & \multicolumn{2}{|l|}{ Overall } & \multicolumn{2}{|l|}{ Male } & \multicolumn{2}{|l|}{ Female } \\
\hline & $\mathrm{B}(95 \% \mathrm{Cl})$ & p & $\mathrm{B}(95 \% \mathrm{Cl})$ & p & $\mathrm{B}(95 \% \mathrm{Cl})$ & $p$ \\
\hline \multicolumn{7}{|l|}{ Social ecological factors } \\
\hline $\begin{array}{l}\text { Don't have enough time to take } \\
\text { sedentary breaks }\end{array}$ & $-0.29(-2.03$ to 1.46$)$ & 0.74 & $1.81(-0.7$ to 4.31$)$ & 0.16 & -0.66 ( -3.65 to 2.32$)$ & 0.66 \\
\hline $\begin{array}{l}\text { Don't have enough energy to take } \\
\text { sedentary breaks }\end{array}$ & -1.61 (- 5.76 to 2.55$)$ & 0.45 & $-4.69(-12.06$ to 2.68$)$ & 0.21 & $-1.27(-7.31$ to 4.78$)$ & 0.68 \\
\hline Sedentary breaks are a low priority. & -0.89 (- 2.31 to 0.52$)$ & 0.22 & $-0.68(-2.29$ to 0.93$)$ & 0.40 & $-1.13(-3.98$ to 1.72$)$ & 0.43 \\
\hline $\begin{array}{l}\text { Too stressed at work to take sedentary } \\
\text { breaks }\end{array}$ & $-1.14(-3.18$ to 0.91$)$ & 0.27 & $-5.6(-9.17$ to -2.02$)$ & $<0.01$ & $-0.29(-3.5$ to 2.93$)$ & 0.86 \\
\hline I am motivated to take sedentary breaks. & $-1.36(-2.61$ to -0.12$)$ & 0.03 & $-0.85(-2.36$ to 0.66$)$ & 0.27 & $-2.37(-4.6$ to -0.13$)$ & 0.04 \\
\hline $\begin{array}{l}\text { I typically see work colleagues take } \\
\text { sedentary breaks. }\end{array}$ & $1.4(0.07$ to 2.73$)$ & 0.04 & $1.03(-0.53$ to 2.58$)$ & 0.19 & $1.55(-0.89$ to 3.99$)$ & 0.21 \\
\hline $\begin{array}{l}\text { The company should encourage } \\
\text { sedentary breaks. }\end{array}$ & $-0.67(-2.35$ to 1$)$ & 0.43 & $-0.1(-2.11$ to 1.9$)$ & 0.92 & $-0.89(-3.97$ to 2.19$)$ & 0.57 \\
\hline $\begin{array}{l}\text { There is limited space available at my } \\
\text { workplace for me to take a short physical } \\
\text { activity break. }\end{array}$ & $0.33(-1.09$ to 1.74$)$ & 0.65 & $-0.37(-2.14$ to 1.39$)$ & 0.67 & $0.37(-2.22$ to 2.96$)$ & 0.78 \\
\hline \multicolumn{7}{|l|}{ Sociodemographic and health factors } \\
\hline Sex (ref: male) & $2.13(0.91$ to 3.34$)$ & $<0.01$ & & & & \\
\hline Age & 0.01 (-0.08 to 0.09$)$ & 0.90 & $-0.06(-0.15$ to 0.03$)$ & 0.22 & $0.12(-0.05$ to 0.28$)$ & 0.16 \\
\hline Residence area (ref: Koto-ku) & 2.31 (1.06 to 3.55 ) & $<0.01$ & 2.71 (1.18 to 4.24 ) & $<0.01$ & 2.13 (-0.17 to 4.42$)$ & 0.07 \\
\hline Education (ref: high school or lower) & $-0.47(-1.15$ to 0.20$)$ & 0.17 & $-0.45(-1.25$ to 0.36$)$ & 0.27 & $-0.36(-1.66$ to 0.94$)$ & 0.58 \\
\hline Income (ref: <5 million) & $-0.22(-0.78$ to 0.35$)$ & 0.45 & $-0.36(-1.01$ to 0.3$)$ & 0.28 & $0.15(-0.98$ to 1.28$)$ & 0.80 \\
\hline Marital status (ref: single) & $1.24(-0.16$ to 2.65$)$ & 0.08 & $0.38(-1.57$ to 2.33$)$ & 0.70 & $1.02(-1.31$ to 3.36$)$ & 0.39 \\
\hline BMI (ref: $<25.0$ kg/m²) & $-1.76(-3.02$ to -0.49$)$ & 0.01 & $-2.18(-3.54$ to -0.82$)$ & $<0.01$ & $-1.13(-4.02$ to 1.76$)$ & 0.44 \\
\hline Weekly MVPA & $0.19(0.00$ to 0.38$)$ & 0.04 & 0.13 (-0.07 to 0.33$)$ & 0.21 & 0.36 (-0.04 to 0.77$)$ & 0.08 \\
\hline Adjusted $R^{2}$ & 0.17 & & 0.23 & & 0.02 & \\
\hline
\end{tabular}

Social-ecological factors were entered as dichotomized variables: 'disagree/strongly disagree $(=1)$ ' and 'agree/strongly agree $(=2)^{\prime}$

$B$ Unstandardized regression coefficient; $B M I$ Body mass index, MVPA Moderate-to-vigorous physical activity

This study expanded the understanding of these associations in the context of a non-Western workplace.

In the overall sample, seeing work colleagues taking sedentary breaks had preferable associations with workplace sedentary breaks. This was also associated with $\geq 30$-min bouts of sedentary time. This finding is consistent with Bennie et al.'s study [7] conducted in women. In a qualitative study, the participants stated that concerns about looking unnaturally or feeling self-conscious were barriers to breaking up sitting and standing time [9]. Some workers find it difficult to stand alone when their colleagues are sitting; therefore, work colleagues taking frequent sedentary breaks may be important to reduce workplace sedentary behavior. In order to provide such opportunities, sedentary breaks in the workplace need to be recommended and habituated at an organization level. For example, as an organizational-level strategy, Hadgraft et al. (2016) proposed some methods that were perceived feasible and acceptable: provision of centralized facilities (e.g., bins, printers), communicating face-to-face, standing during meetings, and so on.
The higher motivation to sedentary breaks was associated with less sedentary breaks and a longer sedentary time. The possible interpretation is that those who have a larger volume of workplace sedentary time may have a motivation to take sedentary breaks. This finding was similar with that of an Australian survey, which reported that those who agreed with the advantages of sitting less were more sedentary at work than those who disagreed with the advantages [8]. Although it is difficult to consider that all workers have the knowledge about the harm of excessive sedentary behavior, some studies reported that a sitting-only work was significantly associated with higher body discomfort compared with sitstand work [23]. Therefore, body discomfort, which more sedentary workers tend to feel, may motivate workers to take sedentary breaks.

In the sex-stratified analysis, too stressed at work to take sedentary breaks was associated with less sedentary breaks and a longer sedentary time in male workers. Bennie et al. [7] reported similar results between too stressed at work to take sedentary breaks and short 
Table 3 Multiple linear regression analyses on the contribution of social-ecological factors to total sedentary time

\begin{tabular}{|c|c|c|c|c|c|c|}
\hline & \multicolumn{2}{|l|}{ Overall } & \multicolumn{2}{|l|}{ Male } & \multicolumn{2}{|l|}{ Female } \\
\hline & $\mathrm{B}(95 \% \mathrm{Cl})$ & $p$ & $\mathrm{~B}(95 \% \mathrm{Cl})$ & $p$ & $\mathrm{~B}(95 \% \mathrm{Cl})$ & $p$ \\
\hline \multicolumn{7}{|l|}{ Social ecological factors } \\
\hline $\begin{array}{l}\text { Don't have enough time to take } \\
\text { sedentary breaks }\end{array}$ & $1.02(-4.40$ to 6.44$)$ & 0.71 & $-8.32(-16.46$ to -0.19$)$ & 0.04 & $5.31(-3.45$ to 14.07$)$ & 0.23 \\
\hline $\begin{array}{l}\text { Don't have enough energy to take } \\
\text { sedentary breaks }\end{array}$ & $4.81(-8.09$ to 17.71$)$ & 0.46 & 17.25 (-6.69 to 41.2$)$ & 0.16 & $2.15(-15.61$ to 19.92$)$ & 0.81 \\
\hline Sedentary breaks are a low priority & $2.18(-2.21$ to 6.57$)$ & 0.33 & $1.91(-3.33$ to 7.14$)$ & 0.47 & $0.99(-7.37$ to 9.35$)$ & 0.81 \\
\hline $\begin{array}{l}\text { Too stressed at work to take } \\
\text { sedentary breaks }\end{array}$ & $5.12(-1.23$ to 11.46$)$ & 0.11 & 18.65 (7.04 to 30.25$)$ & $<0.01$ & $4.99(-4.45$ to 14.44$)$ & 0.30 \\
\hline $\begin{array}{l}\text { I am motivated to take } \\
\text { sedentary breaks. }\end{array}$ & $4.15(0.29$ to 8.00$)$ & 0.04 & $3.52(-1.38$ to 8.43$)$ & 0.16 & $5.52(-1.05$ to 12.09$)$ & 0.10 \\
\hline $\begin{array}{l}\text { I typically see work colleagues take } \\
\text { sedentary breaks. }\end{array}$ & $-2.95(-7.08$ to 1.18$)$ & 0.16 & $-1.9(-6.95$ to 3.15$)$ & 0.46 & $-3.78(-10.95$ to 3.4$)$ & 0.30 \\
\hline $\begin{array}{l}\text { The company should encourage } \\
\text { sedentary breaks. }\end{array}$ & $2.49(-2.72$ to 7.7$)$ & 0.35 & $1.39(-5.13$ to 7.90$)$ & 0.67 & $2.97(-6.08$ to 12.02$)$ & 0.52 \\
\hline $\begin{array}{l}\text { There is limited space available at my } \\
\text { workplace for me to take a short } \\
\text { physical activity break. }\end{array}$ & $-0.18(-4.57$ to 4.2$)$ & 0.93 & $1.83(-3.9$ to 7.57$)$ & 0.53 & $0.95(-6.66$ to 8.55$)$ & 0.80 \\
\hline \multicolumn{7}{|l|}{ Sociodemographic and health factors } \\
\hline Sex (ref: male) & $-6.21(-9.98$ to -2.45$)$ & $<0.01$ & & & & \\
\hline Age & $-0.08(-0.33$ to 0.17$)$ & 0.52 & $0.12(-0.18$ to 0.41$)$ & 0.44 & $-0.46(-0.94$ to 0.03$)$ & 0.06 \\
\hline Residence area (ref: Koto-ku) & $-7.57(-11.44$ to -3.7$)$ & $<0.01$ & $-9.21(-14.19$ to -4.23$)$ & $<0.01$ & $-5.97(-12.72$ to 0.78$)$ & 0.08 \\
\hline Education (ref: high school or lower) & $1.8(-0.29$ to 3.9$)$ & 0.09 & $2.09(-0.53$ to 4.71$)$ & 0.12 & $1(-2.81$ to 4.8$)$ & 0.60 \\
\hline Income (ref: <5 million) & $0.76(-0.98$ to 2.51$)$ & 0.39 & $1.16(-0.96$ to 3.27$)$ & 0.28 & $-0.88(-4.2$ to 2.44$)$ & 0.60 \\
\hline Marital status (ref: single) & $-4.21(-8.57$ to 0.16$)$ & 0.06 & $-1.56(-7.89$ to 4.78$)$ & 0.63 & $-3.3(-10.15$ to 3.56$)$ & 0.34 \\
\hline BMI (Ref: $<25.0 \mathrm{~kg} / \mathrm{m}^{2}$ ) & $4.88(0.95$ to 8.82$)$ & 0.02 & 6.19 (1.77 to 10.61$)$ & 0.01 & $2.15(-6.33$ to 10.63$)$ & 0.62 \\
\hline Weekly MVPA & $-1.01(-1.6$ to -0.43$)$ & $<0.01$ & $-0.92(-1.57$ to -0.27$)$ & 0.01 & $-1.17(-2.36$ to 0.02$)$ & 0.054 \\
\hline Adjusted $R^{2}$ & 0.18 & & 0.26 & & 0.05 & \\
\hline
\end{tabular}

Social-ecological factors were entered as dichotomized variables: 'disagree/strongly disagree $(=1)^{\prime}$ and 'agree/strongly agree $(=2)^{\prime}$

$B$ Unstandardized regression coefficient; BMI Body mass index, MVPA Moderate-to-vigorous physical activity

physical activity breaks. Male workers may have sitting tasks, which makes it difficult for them to take sedentary breaks, or may not be willing to take breaks at work. In the previous qualitative studies on workplace sedentary behavior, the participants stated the nature of the job as a barrier to reduce sedentary behavior [9, 24]. For example, computer-based work and the pressure of having a heavier workload hindered the reduction in sedentary behavior, which we also observed from our sample. Although there is a need to examine the details of the stress at work that hindered one to take a sedentary break, sit-stand workstation may resolve the problem "too stressed at work to take sedentary breaks" because it enables workers to stand without interrupting their job [25] and does not decrease work productivity [23].

In addition, male workers responded that not having enough time to take sedentary breaks was associated with less sedentary time, which was similar to the reports of Bennie et al.'s study (2011). Our results suggest that such male workers were likely to had less sedentary time than those who felt that they had enough time to take sedentary breaks. Therefore, male workers who felt that they did not have enough time to take sedentary breaks may opt to relatively stand at work. For female workers, no correlates were found, except for the motivation to take sedentary breaks. The adjusted $R^{2}$ value in the three models for female workers was relatively low $(0.02$ to 0.05 , Tables $2,3,4)$, which suggests that it is difficult to explain the correlation between workplace sedentary behavior of female workers and social-ecological factors. Because previous studies reported some correlates for female workers [7, 13], further research is needed to verify these results.

The strength of the present study was that sedentary behavior and physical activity were objectively assessed using triaxial accelerometers. This method contains no recall bias compared with a self-report assessment tool. Another strength was that the participants were recruited from a randomly sampled population living in two different cities, which allowed the collection of data 
Table 4 Multiple linear regression analyses on the contribution of social ecological factors to $\geq 30$ min bouts of sedentary time

\begin{tabular}{|c|c|c|c|c|c|c|}
\hline & \multicolumn{2}{|l|}{ Overall } & \multicolumn{2}{|l|}{ Male } & \multicolumn{2}{|l|}{ Female } \\
\hline & $\mathrm{B}(95 \% \mathrm{Cl})$ & $p$ & $\mathrm{~B}(95 \% \mathrm{Cl})$ & $p$ & $\mathrm{~B}(95 \% \mathrm{Cl})$ & $p$ \\
\hline \multicolumn{7}{|l|}{ Social ecological factors } \\
\hline $\begin{array}{l}\text { Don't have enough time to take } \\
\text { sedentary breaks }\end{array}$ & $-0.96(-9.72$ to 7.79$)$ & 0.83 & $-11.78(-25.31$ to 1.76$)$ & 0.09 & $-0.07(-13.57$ to 13.44$)$ & 0.99 \\
\hline $\begin{array}{l}\text { Don't have enough energy to take } \\
\text { sedentary breaks }\end{array}$ & $3.95(-16.9$ to 24.81$)$ & 0.71 & $24.39(-15.44$ to 64.22$)$ & 0.23 & $-2.79(-30.16$ to 24.57$)$ & 0.84 \\
\hline Sedentary breaks are a low priority. & $3.43(-3.67$ to 10.54$)$ & 0.34 & $3.54(-5.17$ to 12.25$)$ & 0.42 & $6.37(-6.51$ to 19.25$)$ & 0.33 \\
\hline $\begin{array}{l}\text { Too stressed at work to take } \\
\text { sedentary breaks }\end{array}$ & $7.78(-2.48$ to 18.05$)$ & 0.14 & 34.79 (15.48 to 54.09$)$ & $<0.01$ & $2.08(-12.47$ to 16.62$)$ & 0.78 \\
\hline $\begin{array}{l}\text { I am motivated to take } \\
\text { sedentary breaks. }\end{array}$ & $2.91(-3.33$ to 9.14$)$ & 0.36 & $1.33(-6.83$ to 9.49$)$ & 0.75 & $5.77(-4.35$ to 15.9$)$ & 0.26 \\
\hline $\begin{array}{l}\text { I typically see work colleagues take } \\
\text { sedentary breaks. }\end{array}$ & $-7.08(-13.75$ to -0.40$)$ & 0.04 & $-4.21(-12.61$ to 4.19$)$ & 0.32 & $-8.89(-19.95$ to 2.16$)$ & 0.11 \\
\hline $\begin{array}{l}\text { The company should encourage } \\
\text { sedentary breaks. }\end{array}$ & $8.2(-0.21$ to 16.62$)$ & 0.06 & $2.49(-8.35$ to 13.32$)$ & 0.65 & $9.17(-4.78$ to 23.12$)$ & 0.19 \\
\hline $\begin{array}{l}\text { There is limited space available at my } \\
\text { workplace for me to take a short } \\
\text { physical activity break. }\end{array}$ & $-1.53(-8.62$ to 5.56$)$ & 0.67 & $2.34(-7.2$ to 11.88$)$ & 0.63 & $-2.29(-14.01$ to 9.43$)$ & 0.70 \\
\hline \multicolumn{7}{|l|}{ Sociodemographic and health factors } \\
\hline Sex (ref: male) & $-11.09(-17.18$ to -5.01$)$ & $<0.01$ & & & & \\
\hline Age & $-0.15(-0.56$ to 0.25$)$ & 0.46 & $0.16(-0.33$ to 0.65$)$ & 0.52 & $-0.52(-1.27$ to 0.22$)$ & 0.17 \\
\hline Residence area (ref: Koto-ku) & $-7.6(-13.85$ to -1.34$)$ & 0.02 & $-11.4(-19.68$ to -3.12$)$ & 0.01 & $-2.84(-13.23$ to 7.56$)$ & 0.59 \\
\hline Education (ref: high school or lower) & $1.95(-1.43$ to 5.33$)$ & 0.26 & $-0.86(-5.22$ to 3.50$)$ & 0.70 & $5.70(-0.16$ to 11.56$)$ & 0.06 \\
\hline Income (ref: <5 million) & $0.97(-1.85$ to 3.79$)$ & 0.50 & $1.79(-1.74$ to 5.31$)$ & 0.32 & $-0.02(-5.14$ to 5.09$)$ & 0.99 \\
\hline Marital status (ref: single) & $-5.7(-12.75$ to 1.36$)$ & 0.11 & $2.67(-7.87$ to 13.21$)$ & 0.62 & $-8.84(-19.41$ to 1.73$)$ & 0.10 \\
\hline BMI (Ref: <25.0 kg/m²) & $8.98(2.63$ to 15.34$)$ & 0.01 & $10.0(2.64$ to 17.35$)$ & 0.01 & $11.86(-1.21$ to 24.93$)$ & 0.07 \\
\hline Weekly MVPA & $-0.79(-1.74$ to 0.15$)$ & 0.10 & $-0.82(-1.9$ to 0.26$)$ & 0.13 & $-0.85(-2.68$ to 0.98$)$ & 0.36 \\
\hline Adjusted $R^{2}$ & 0.13 & & 0.16 & & 0.04 & \\
\hline
\end{tabular}

Social-ecological factors were entered as dichotomized variables: 'disagree/strongly disagree $(=1)^{\prime}$ and 'agree/strongly agree $(=2)$ '

$B$ Unstandardized regression coefficient; BMI Body mass index, MVPA Moderate-to-vigorous physical activity

from various workplaces and occupations. This study had some limitations. First, as a cross-sectional study, the causal relationship between the social-ecological factors and workplace sedentary behavior cannot be detected. Second, the number of female workers was small; hence, it may be insufficient to detect significant correlates. Third, the validity of social-ecological factors cannot be shown because the factors depend on the subjective response, and there were no established criteria to measure validity. The present study assessed temporary subjective response of the factors; therefore, the reliability and reproducibility of the response could not be confirmed.

\section{Conclusions}

The present study found that some social-ecological factors were associated with workplace sedentary behavior among Japanese sedentary workers. Our findings suggest that seeing work colleagues take sedentary breaks is associated with more sedentary breaks at work. Organizational strategies to reduce workplace sedentary behavior may be important. Those who are more sedentary may have the motivation to take sedentary breaks. For male workers, the stress at work that hinders them from taking sedentary breaks remains an issue. Hence, further research using a large sample size and with a prospective design is needed to confirm these findings.

\section{Supplementary information}

Supplementary information accompanies this paper at https://doi.org/10 1186/s12889-019-7782-1.

Additional file 1. Questionnaire of the social-ecological factors for sedentary breaks at work.

\section{Abbreviations}

B: Unstandardized regression coefficient;; BMI: Body Mass Index;

Cl: Confidence intervals; METs: Metabolic equivalents; MVPA: Moderate-to-

Vigorous Physical Activity

Acknowledgements

The authors would like to thank all the participants in the study. 


\section{Authors' contributions}

$\mathrm{KO}$ made significant contributions to study design. SK, KI, AS and KO collected the data, and helped in interpretation of analysis, and all statistical analysis was completed by SK. SK prepared the first draft of the paper, and $\mathrm{Kl}, \mathrm{AS}, \mathrm{MJK}$ and $\mathrm{KO}$ made a substantial contribution in revising the draft. All authors have read and approved the manuscript.

\section{Funding}

SK was supported by Grant-in-Aid for Scientific Research (Early-Career Scientists: No. 18 K17995) from Japan Society for the Promotion of Science. AS was supported by Grant-in-Aid for Scientific Research (C: No. 18 K10986) from Japan Society for the Promotion of Science. MJK was supported by a JSPS Postdoctoral Fellowship for Research in Japan (\#17716) from the Japan Society for the Promotion of Science. KO was supported by the MEXT-Supported Program for the Strategic Research Foundation at Private Universities, 20152019 the Japan Ministry of Education, Culture, Sports, Science and Technology (S1511017) and a Grants-in-Aid for Scientific Research (No. 26242070) from the Japan Society for the Promotion of Science. These funding bodies didn't participate in the design of the study and collection, analysis, and interpretation of data and in writing the manuscript.

\section{Availability of data and materials}

The datasets used in this study may be available upon reasonable request to the corresponding author.

\section{Ethics approval and consent to participate}

The study was approved by the Research Ethics Committee, Waseda University, Japan. Written informed consent was obtained from participants.

\section{Consent for publication}

Not applicable.

\section{Competing interests}

The authors declare that there are no competing interests.

AS, an associate editor of this journal had no role in the editorial process.

\section{Author details}

'Department of Preventive Gerontology, Center for Gerontology and Social Science, National Center for Geriatrics and Gerontology, Obu, Aichi, Japan. ${ }^{2}$ Faculty Health and Sport Sciences, University of Tsukuba, Tsukuba, Ibaraki, Japan. ${ }^{3}$ Faculty of Sport Sciences, Waseda University, Tokorozawa, Saitama, Japan. ${ }^{4}$ Mary Mackillop Institute for Health Research, Australian Catholic University, Melbourne, Victoria, Australia. ${ }^{5}$ Behavioural Epidemiology Laboratory, Baker Heart \& Diabetes Institute, Melbourne, Victoria, Australia.

Received: 22 July 2019 Accepted: 15 October 2019

Published online: 08 November 2019

\section{References}

1. Biswas A, Oh PI, Faulkner GE, Bajaj RR, Silver MA, Mitchell MS, et al. Sedentary time and its association with risk for disease incidence, mortality, and hospitalization in adults: a systematic review and meta-analysis. Ann Intern Med. 2015;162(2):123-32.

2. de Rezende LF, Rey-Lopez JP, Matsudo VK, do Carmo Luiz O. Sedentary behavior and health outcomes among older adults: a systematic review. BMC Public Health. 2014;14:333.

3. Church TS, Thomas DM, Tudor-Locke C, Katzmarzyk PT, Earnest CP, Rodarte $\mathrm{RQ}$, et al. Trends over 5 decades in U.S. occupation-related physical activity and their associations with obesity. PLoS One. 2011;6(5):e19657.

4. Kurita S, Shibata A, Ishii K, Koohsari MJ, Owen N, Oka K. Patterns of objectively-assessed sedentary time and physical activity among Japanese workers: cross-sectional study. BMJ Open. 2018; in press.

5. Chu AH, Ng SH, Tan CS, Win AM, Koh D, Muller-Riemenschneider F. A systematic review and meta-analysis of workplace intervention strategies to reduce sedentary time in white-collar workers. Obes Rev. 2016;17(5):467-81.

6. Shrestha N, Kukkonen-Harjula KT, Verbeek JH, ljaz S, Hermans V, Pedisic Z. Workplace interventions for reducing sitting at work. Cochrane Database Syst Rev. 2018;6:CD010912.

7. Bennie JA, Timperio AF, Crawford DA, Dunstan DW, Salmon JL. Associations between social ecological factors and self-reported short physical activity breaks during work hours among desk-based employees. Prev Med. 2011; 53(1-2):44-7.

8. De Cocker K, Duncan MJ, Short C, van Uffelen JG, Vandelanotte C. Understanding occupational sitting: prevalence, correlates and moderating effects in Australian employees. Prev Med. 2014;67:288-94.

9. Hadgraft NT, Brakenridge CL, LaMontagne AD, Fjeldsoe BS, Lynch BM, Dunstan DW, et al. Feasibility and acceptability of reducing workplace sitting time: a qualitative study with Australian office workers. BMC Public Health. 2016;16:933.

10. Mullane SL, Toledo MJL, Rydell SA, Feltes LH, Vuong B, Crespo NC, et al. Social ecological correlates of workplace sedentary behavior. Int J Behav Nutr Phys Act. 2017;14(1):117.

11. Uijtdewilligen $L$, Yin $J D$, van der Ploeg HP, Muller-Riemenschneider $F$. Correlates of occupational, leisure and total sitting time in working adults: results from the Singapore multi-ethnic cohort. Int I Behav Nutr Phys Act. 2017;14(1):169.

12. van Dommelen P, Coffeng JK, van der Ploeg HP, van der Beek AJ, Boot CR, Hendriksen IJ. Objectively measured total and occupational sedentary time in three work settings. PLoS One. 2016;11(3):e0149951.

13. Wallmann-Sperlich B, Bucksch J, Schneider S, Froboese I. Sociodemographic, behavioural and cognitive correlates of work-related sitting time in German men and women. BMC Public Health. 2014;14:1259.

14. Waters CN, Ling EP, Chu AH, Ng SH, Chia A, Lim YW, et al. Assessing and understanding sedentary behaviour in office-based working adults: a mixedmethod approach. BMC Public Health. 2016;16:360.

15. Sallis JF, Owen N, Fisher E. Ecological models of health behavior. Health behav Theory Res Pract. 2015;5:43-64.

16. Ishii K, Shibata A, Kurita S, Yano S, Inoue S, Sugiyama T, et al. Validity and reliability of Japanese-language self-reported measures for assessing adults domain-specific sedentary time. J Epidemiol. 2018;28(3):149-55.

17. Ohkawara K, Oshima Y, Hikihara Y, Ishikawa-Takata K, Tabata I, Tanaka S. Real-time estimation of daily physical activity intensity by a triaxial accelerometer and a gravity-removal classification algorithm. Br J Nutr. 2011; 105(11):1681-91.

18. Oshima Y, Kawaguchi K, Tanaka S, Ohkawara K, Hikihara Y, Ishikawa-Takata K, et al. Classifying household and locomotive activities using a triaxial accelerometer. Gait Posture. 2010;31(3):370-4.

19. Kurita S, Yano S, Ishii K, Shibata A, Sasai H, Nakata Y, et al. Comparability of activity monitors used in Asian and Western-country studies for assessing free-living sedentary behaviour. PLoS One. 2017;12(10):e0186523.

20. Thorp AA, Healy GN, Winkler E, Clark BK, Gardiner PA, Owen N, et al. Prolonged sedentary time and physical activity in workplace and non-work contexts: a cross-sectional study of office, customer service and call Centre employees. Int J Behav Nutr Phys Act. 2012;9:128.

21. Tremblay MS, Aubert S, Barnes JD, Saunders TJ, Carson V, Latimer-Cheung $A E$, et al. Sedentary behavior research network (SBRN) - terminology consensus project process and outcome. Int J Behav Nutr Phys Act. 2017; 14(1):75.

22. Lee JW, Jones PS, Mineyama Y, Zhang XE. Cultural differences in responses to a Likert scale. Res Nurs Health. 2002;25(4):295-306.

23. Karakolis T, Callaghan JP. The impact of sit-stand office workstations on worker discomfort and productivity: a review. Appl Ergon. 2014;45(3):799-806.

24. Cole JA, Tully MA, Cupples ME. "They should stay at their desk until the work's done": a qualitative study examining perceptions of sedentary behaviour in a desk-based occupational setting. BMC Res Notes. 2015;8:683.

25. Alkhajah TA, Reeves MM, Eakin EG, Winkler EA, Owen N, Healy GN. Sit-stand workstations: a pilot intervention to reduce office sitting time. Am J Prev Med. 2012;43(3):298-303.

\section{Publisher's Note}

Springer Nature remains neutral with regard to jurisdictional claims in published maps and institutional affiliations. 